\title{
Characterisation of Growth and Ultrastructural Effects of the Xanthoria elegans Photobiont After 1.5 Years of Space Exposure on the International Space Station
}

\author{
Annette Brandt $^{1}$ - Eva Posthoff ${ }^{1}$ - Jean-Pierre de Vera ${ }^{2}$. \\ Silvano Onofri ${ }^{3} \cdot$ Sieglinde Ott ${ }^{1}$
}

Received: 1 October 2015 / Accepted: 5 October 2015

(C) Springer Science+Business Media Dordrecht 2015

\begin{abstract}
The lichen Xanthoria elegans has been exposed to space and simulated Mars-analogue environment in the Lichen and Fungi Experiment (LIFE) on the EXPOSE-E facility at the International Space Station (ISS). This long-term exposure of 559 days tested the ability of various organisms to cope with either low earth orbit (LEO) or Mars-analogue conditions, such as vacuum, Mars-analogue atmosphere, rapid temperature cycling, cosmic radiation of up to $215 \pm 16 \mathrm{mGy}$, and insolation of accumulated doses up to $4.87 \mathrm{GJm}^{-2}$, including up to $0.314 \mathrm{GJm}^{-2}$ of UV irradiation. In a previous study, $X$. elegans demonstrated considerable resistance towards these conditions by means of photosynthetic activity as well as by post-exposure metabolic activity of $50-80 \%$ in the algal and $60-90 \%$ in the fungal symbiont (Brandt et al. Int J Astrobiol 14(3):411$425,2015)$. The two objectives of the present study were complementary: First, to verify the high post-exposure viability by using a qualitative cultivation assay. Second, to characterise the cellular damages by transmission electron microscopy (TEM) which were caused by the space and Marsanalogue exposure conditions of LIFE. Since the algal symbiont of lichens is considered as the more susceptible partner (de Vera and Ott 2010), the analyses focused on the photobiont. The study demonstrated growth and proliferation of the isolated photobiont after all exposure conditions of LIFE. The ultrastructural analysis of the algal cells provided an insight to cellular damages caused by long-term exposure and highlighted that desiccation-induced breakdown of
\end{abstract}

Paper presented at the 14th European Astrobiology Conference (EANA 2014) held 13-16 October 2014 in Edinburgh, United Kingdom.

Sieglinde Ott

otts@uni-duesseldorf.de

1 Institute of Botany, Heinrich-Heine-University (HHU), Universitaetsstr. 1, 40225 Duesseldorf, Germany

2 Institute of Planetary Research, German Aerospace Center (DLR), Rutherfordstr. 2, 12489 Berlin, Germany

3 Department of Ecological and Biological Sciences (DEB), Tuscia University, Largo dell'Università, 01100 Viterbo, Italy 
cellular integrity is more pronounced under the more severe space vacuum than under Marsanalogue atmospheric conditions. In conclusion, desiccation-induced damages were identified as a major threat to the photobiont of $X$. elegans. Nonetheless, a fraction of the photobiont cells remained cultivable after all exposure conditions tested in LIFE.

Keywords Astrobiology $\cdot$ Expose-E $\cdot$ Life $\cdot$ Lichen $\cdot$ Space conditions $\cdot$ Mars-analogue conditions

$\begin{array}{ll}\text { Abbreviations } \\ \text { ISS } & \text { International Space Station } \\ \text { LEO } & \text { low Earth orbit } \\ \text { LIFE } & \text { Lichen and Fungi Experiment } \\ \text { MGR } & \text { Mission Ground Reference } \\ \text { T } & \text { transmission } \\ \text { TEM } & \text { transmission electron microscopy } \\ \text { UV } & \text { ultraviolet radiation }\end{array}$

\section{Introduction}

Since the beginning of the new millennium, various astrobiological experiments were conducted to test the effects of space and Mars-analogue conditions on lichens, mosses, fungi and prokaryotes. These simulation experiments tested the single or combined effects of vacuum up to $10^{-5} \mathrm{~Pa}$ and UV-radiation (de Vera et al. 2003, 2004a, 2004b, 2008, 2010; de La Vega et al. 2007; de Vera \& Ott 2010; Sánchez et al. 2012, 2014; Baqué et al. 2013; Meeßen et al. 2014), hypervelocity impact pressures up to $50 \mathrm{GPa}$ (Stöffler et al. 2007; Horneck et al. 2008), but also tested the resistance to other space-related parameters as freezing and drought (Onofri et al. 2004; Hájek et al. 2012; Meeßen et al., 2014). Additionally, the lichen Xanthoria elegans was part of the space exposure experiments LICHENS II on BIOPAN 5, LITHOPANSPERMIA on BIOPAN 6 (Sancho et al. 2007; de la Torre et al. 2007, 2010; Olsson-Francis et al., 2010; Raggio et al. 2011) and consequently became part of the Lichen and Fungi Experiment (LIFE) on EXPOSE-E/ EUTEF at the ISS where it was exposed among other organisms to space and simulated Mars conditions for 18 months (Cockell et al. 2011; Onofri et al. 2012; Rabbow et al. 2012; Scalzi et al. 2012; Brandt et al. 2015). The EXPOSE-E facility provided LEO-space vacuum $\left(10^{-4}\right.$ to $\left.10^{-7} \mathrm{~Pa}\right)$ and simulated Mars conditions $\left(10^{3} \mathrm{~Pa}\right.$ Mars-analogue atmosphere) under three different insolation regimes of $100 \%$ transmission, $0.1 \%$ transmission (T) and no insolation as described below, leading to accumulated insolation doses up to $4.87 \mathrm{GJm}^{-2}$ and UV irradiation doses of up to 314 $\mathrm{MJm}^{-2}$ at the sample sites of $X$. elegans.

The astrobiological model lichen $X$. elegans is a symbiotic association of an ascomycete fungus (mycobiont) and a coccal green alga (photobiont, genus Trebouxia). This cosmopolite lichen is well adapted to harsh environmental conditions as found in high alpine and polar regions (Øvstedal \& Lewis Smith 2001). It is characterized by the secondary lichen compound parietin known for its high light- and UV-screening capacities (Solhaug \& Gauslaa 1996; Solhaug et al. 2003, 2010). To assess its limits of survival after LIFE, X.elegans was tested on its resistance to the applied conditions and the exposure-induced decrease of post-exposure viability by chlorophyll $a$ fluorescence and live/dead staining analyses (Onofri et al. 2012; Brandt et al. 2015). Both methods revealed high rates of metabolic and photosynthetic activity. 
The live/dead staining results of the photobiont revealed viability rates of 50-80\%, while the more resistant mycobiont showed rates of $60-90 \%$. The photosynthetic re-activation of the photobiont depended on the exposure conditions. Vacuum exposed and fully insolated $(100 \%$ transmission) samples took 8 days of re-activation to reach c. $45 \%$ of its pre-flight maximum quantum yield of photosystem II while the Mars-analogue samples of all insolation conditions returned to pre-flight values within 4 days (Onofri et al. 2012, Brandt et al. 2015).

The present study conducted a qualitative cultivation assay of the isolated photobiont to corroborate the $50-80 \%$ of remaining metabolic activity and the photosynthetic re-activation of $X$. elegans as indicators of post-flight viability. This assay confirmed the viability of photobiont cells/clusters after 1.5 years of space exposure by growth and proliferation, i.e.by its ability to perform complete cell cycles. The present study demonstrates a capacity of survival beyond the metabolic and photosynthetic activities reported before (Onofri et al. 2012, Brandt et al. 2015). Complementary, the analysis by transmission electron microscopy (TEM) also investigated the impact of extreme desiccation on photobiont ultrastructure as induced by 1.5 year exposure to space vacuum and Mars-analogue atmosphere conditions. This part of the study aimed to characterise the impairment on the cellular level by vacuum and low atmospheric pressure that may explain the loss of 20-50\% of algal viability observed in previous studies (Brandt et al. 2015). Both parts of the present study focused on the isolated photobiont, as it is described to be the more sensitive symbiotic partner towards simulated space and Martian conditions (de Vera et al. 2003, 2008; de Vera \& Ott 2010).

\section{Material and Methods}

Lichen Samples Samples of Xanthoria elegans (Link) Th. Fr. (1860) were collected in

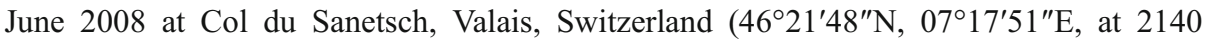
$\mathrm{m}$ a.s.1.) and adjacent collection sites (Zermatt, $46^{\circ} 00^{\prime} \mathrm{N}, 07^{\circ} 71^{\prime} \mathrm{E}$, at $1950 \mathrm{~m}$ a.s.1.). Samples originating from this collection sites were used in astrobiological studies before (de Vera et al. 2003, 2004a, 2004b, 2008, 2010) and consistently showed high viability after these studies.

Exposure Conditions The samples were exposed in the EXPOSE-E facility outside the European Columbus Module at the ISS for 559 days. Six experimental conditions were realised: Eight samples each were exposed to space (tray 1) and Mars-analogue conditions (tray 2). Tray 1 provided $10^{-4}$ to $10^{-7} \mathrm{~Pa}$ LEO-vacuum and three intensities of solar radiation (dark, $0.1 \%$ transmission by neutral density filters, and $100 \%$ transmission (T)) from 110 $\mathrm{nm}\langle\lambda\rangle 1 \mathrm{~mm}$ (covered with $\mathrm{MgF}_{2}$ windows) while tray 2 provided simulated Mars conditions with a $10^{3} \mathrm{~Pa}$ atmosphere $\left(95.3 \% \mathrm{CO}_{2}, 2.7 \% \mathrm{~N}_{2}, 1.6 \% \mathrm{Ar}, 0.15 \% \mathrm{O}_{2}, \sim 370\right.$ ppm water vapour) and again three intensities of solar irradiation (as above) from 200 $\mathrm{nm}\langle\lambda>1 \mathrm{~mm}$ (covered by Suprasil quartz windows). At the sample sites, fully insolated samples accumulated an average of $4800 \mathrm{MJm}^{-2}$ photon energy input; $0.1 \%$ transmission samples accumulated $6.3 \mathrm{MJm}^{-2}$ photon energy in tray 1 and $5.9 \mathrm{MJm}^{-2}$ in tray 2 . The portions of UV-irradiation ranged from $291 \mathrm{MJm}^{-2}$ at $100 \% \mathrm{~T}$ to $0.271 \mathrm{MJm}^{-2}$ at $0.1 \% \mathrm{~T}$ under space conditions $(110 \mathrm{~nm}<\lambda>400 \mathrm{~mm})$ and from $314 \mathrm{MJm}^{-2}$ at $100 \% \mathrm{~T}$ to $0.257 \mathrm{MJm}^{-2}$ at $0.1 \% \mathrm{~T}$ under Mars conditions $(200 \mathrm{~nm}<\lambda>400 \mathrm{~mm})$. The samples experienced ionizing radiation of $208 \pm 8 \mathrm{mGy}$ in tray 1 , and $215 \pm 16 \mathrm{mGy}$ in tray 2 (Berger et al. 2012) and a temperature range from -21.7 to $+43^{\circ} \mathrm{C}$ with a short-time maximum of $61^{\circ} \mathrm{C}$ and 100 freeze/thaw cycles (Rabbow et al. 2012). According to the data received from the EXPOSE-E facility, a 
corresponding set of samples was exposed to as similar as possible simulated conditions, referred to as Mission Ground Reference (MGR; Rabbow et al. 2012). Due to off-nominal events during the mission about $20 \%$ of the expected environmental data were lost. To assure precise sample analysis of the exposure conditions the solar irradiation was recalculated (RedShift Report 2011) leading to accumulated irradiance values differing from those given in Rabbow et al. (2012). During LIFE the lichen samples stayed in anhydrobiotic state during the whole experiment. After return all samples were stored frozen $\left(-20^{\circ} \mathrm{C}\right)$ until further investigations.

Culture Assay The symbiotic algae were prepared from the lichen sample under sterile conditions, using a hollow needle and a scalpel to place algal clusters immediately on Trebouxia Organic Medium agar-plates (Ahmadjian 1967) and BG11 medium. Amphotericin-B $(5 \mu \mathrm{g} / \mathrm{ml})$ and Ampicillin $(200 \mu \mathrm{g} / \mathrm{ml})$ were added to both media to prevent fungal and bacterial contamination. 10-15 colonies per agar-plate and per media were inoculated for each experimental condition, including untreated controls. The cultivation took place at $12^{\circ} \mathrm{C}$ under $14 \mathrm{~h}$ daytime photosynthetic photon flux density of $15-25 \mu \mathrm{molm}^{-2} \mathrm{~s}^{-1}$. Algal colonies were inspected daily to detect contaminations and were re-inoculated on sterile media in case of visible contamination. Growing colonies were photo-documented using a stereo microscope (Zeiss, Germany) with a digital camera (Pentax). After 200 days of cultivation the experiment was concluded. For subsequent studies the algae were transferred to glycerin stocks and stored at $-20^{\circ} \mathrm{C}$.

Transmission Electron Microscopy (TEM) Sample pieces of lichen thalli of all exposure conditions (c. $2 \mathrm{~mm}$ in diameter) were fixed in $2.5 \%$ glutaraldehyde (in $200 \mathrm{mM}$ cacodylatebuffer), contrasted in $4 \% \mathrm{OsO}_{4}$ (in $0.8 \%$ potassium ferrocyanide), and dried by graduated dilution series of ethanol and acetone prior to critical point drying (CPD 020, Balzers Union). The fixed samples were embedded in Epon812 resin following the manufacturer's protocol and ultrathin cross-sections $(100 \mathrm{~nm})$ were examined with a Zeiss E902 TEM. To test the effect of prolonged dry storage, two different controls were chosen: one from dry storage over silicagel, the other was kept in the freezer at $-20^{\circ} \mathrm{C}$. Cell counting was performed manually using the Image J counter tool (v1.49 $\mathrm{m}$ Wayne Rasband). Image processing of the micrographs was done with Fiji macros (Biovoxxel 2014). For statistical analyses (one-way ANOVA with posttest) GraphPad InStat3 was applied (GraphPad software 2003).

Explanation of Ultrastructural Terminology Cell wall: rigid layer surrounding the protoplast of plant cells; protoplast: plant cell without its cell wall; thylakoid: compartment of the chloroplast where thylakoid membranes enclose the thylakoid lumen, site of light-dependent reaction of photosynthesis; pyrenoid: compartment of the chloroplast, spherical protein structure, site of $\mathrm{CO}_{2}$-fixation; pyrenoglobuli: osmiophilic, electron-dense globuli of uncertain function, most likely sites of lipid storage; grana: thylakoid membrane stacks in the chloroplast.

\section{Results}

Culture Assay For the first time, it was possible to cultivate lichen photobionts after longterm space exposure. Proliferating algal cultures were achieved from all three insolation regimes investigated in the LIFE experiment and under both, space vacuum and Mars- 
analogue conditions. The algal colonies from different exposure conditions revealed qualitative differences in proliferation rate and final colony size (Figs. 1 and 2) while the control group samples showed the fastest growth. They formed larger colonies in equivalent periods of time when compared to all experimental conditions tested. By comparing the ratio of initially inoculated algal clusters to grown colonies, the results indicate that exposure to Mars-analogue conditions had less effects on the proliferation abilities when compared to the algal colonies derived from space vacuum exposure conditions (Table 1). Colonies from Mars-analogue exposure conditions grew faster and became larger in size in the respective time. Despite varying by three orders of magnitude, the different insolation conditions (no insolation, $0.1 \% \mathrm{~T}$, and $100 \% \mathrm{~T}$ ) had no visible effect on the samples exposed to Mars-analogue conditions (Fig. 2). Compared to Mars-analogue conditions, the vacuum exposed samples showed an overall reduction in proliferation and colony-forming ratio. In general, the viability of non-insolated samples was not increased compared to irradiated ones. In line with previous investigations on the metabolic activity (Brandt et al. 2015), the present results indicate that insolation, especially UV-irradiation, seems not to be the crucial factor affecting post-exposure viability under the experimental conditions tested. Among the cultivated photobionts one mycelium arose putatively from co-isolated hyphae and was transferred to malt-yeast media (Fig. 2) for further cultivation.

Ultrastructural Analyses by TEM The current analysis focused on the ultrastructural impairment of the photobiont of Xanthoria elegans to investigate damaging to lethal effects experienced during LIFE. Detailed analysis of the micrographs revealed distinct ultrastructural features of algal degeneration. Collapses of the cell or of the protoplast alone were frequently recognised and served as markers of exposure-induced damages. Under all investigated exposure conditions, a portion of photobiont cells showed partial or complete collapse of the protoplast with or without cell wall deformation (Fig. 3A-C). The frequency of cellular collapses differed between dry-stored and frozen control group. Dry-stored control samples showed a significantly higher amount of protoplast (70 \%) and cell wall collapses (49\%) compared to frozen ones (44\% and $33 \%$, respectively) indicating a more deleterious effect of long-term desiccation than freezing (Table 2). The intensity of damage also differed between samples exposed to Mars-analogue atmosphere and space vacuum but none of the irradiation conditions correlated to the percentage of cell wall and protoplast collapses. Exposure to Marsanalogue atmosphere of $10^{3} \mathrm{~Pa}$ caused comparable numbers of protoplast collapses $(57 \%$, $48 \%, 51 \%$ at non-irradiated, $0.1 \% \mathrm{~T}$ and $100 \% \mathrm{~T}$, respectively). Exposure to vacuum $\left(10^{-4}\right.$ to $\left.10^{-7} \mathrm{~Pa}\right)$ showed higher numbers of collapsed protoplasts $(61 \%, 97 \%, 85 \%)$ even when compared to the dry control samples. Except for the non-irradiated samples, deformed cell walls occurred in space vacuum samples in higher percentage when compared to Marsanalogue conditions $(25 \%, 79 \%, 85 \%$ compared to $27 \%, 16 \%, 35 \%$, Table 2). The MGR data confirmed these results. The MGR simulation of Mars-analogue conditions caused
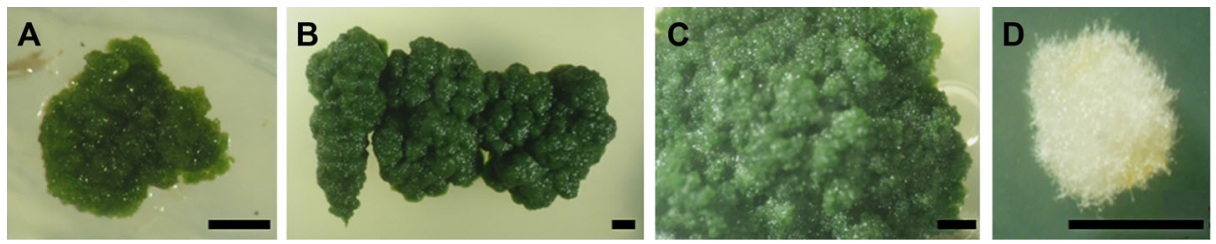

Fig. 1 Photobiont cultivation assay of samples exposed to space vacuum. Algal colonies after space vacuum exposure, cultivation duration c. 200 days. a $100 \%$ T. b $0.1 \%$ T. c no insolation. d $0.1 \%$ T, picture shows one mycobiont colony of $X$. elegans. Scale bars indicate $1 \mathrm{~mm}$ 

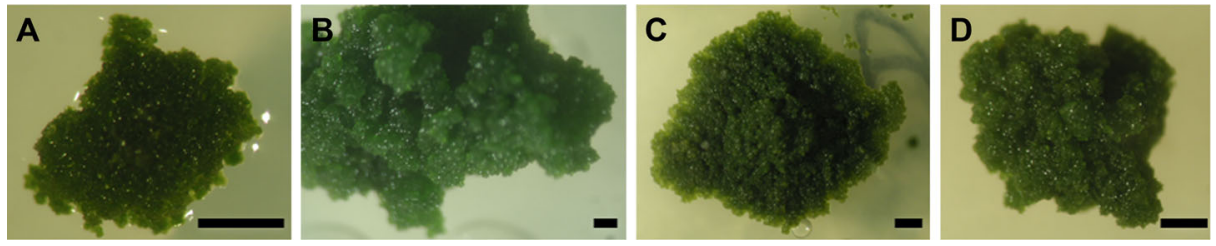

Fig. 2 Photobiont cultivation assay of samples exposed to Mars-analogue conditions. Algal colonies after Marsanalogue exposure, cultivation duration ca. 200 days: a $100 \%$ T. b $0.1 \%$ T. c no insolation. d Control (stored at $\left.-20^{\circ} \mathrm{C}\right)$. Scale bars indicate $1 \mathrm{~mm}$

$40-42 \%$ of collapsed protoplasts while the MGR simulation of space vacuum led to $52-86 \%$ of collapsed protoplasts.

Based on previous observations (Brown et al. 1987; Ascaso et al. 1988, 1995; Honegger 2003), changes in pyrenoid structure, localisation and appearance of pyrenoglobuli, degraded grana, and degraded thylakoid membranes were taken as additional markers of desiccationinduced cellular damage (Fig. 4). The degree of thylakoid membrane degradation and pyrenoid-enlargement was moderate in the frozen control and more pronounced in the dry control (Fig. 4 a). Even more pronounced thylakoid membrane degradation was observed in samples from space vacuum exposure and Mars-analogue exposure (Fig. 4 b-c). The pyrenoidenlargement and appearance of pyrenoglobuli were observed to various extent but did not correlate to the experimental conditions applied (Fig. 4 d-e). Pyrenoglobuli were documented in all samples except in non- and $0.1 \%$-insolated Mars-analogue samples and appeared most frequently in the frozen control group (Fig. 4 f).

In general, the ultrastructural markers of thylakoid membrane degradation, cell wall and protoplast collapse indicate that the extreme and long-term desiccation of space vacuum and less effective - Mars atmospheric pressure was the major impairment factor of the exposure conditions of LIFE. However, any LIFE exposure condition enhanced the observed degradation patterns of photobiont cells when compared to the two control samples.

\section{Discussion}

Post-Exposure Viability The present study verified the viability of the lichen photobiont of Xanthoria elegans after 18 months under the extreme conditions of LEO-space exposure by demonstrating the photobiont's ability to grow and proliferate after isolation from the thallus. These results are consistent with the results of previous quantitative analyses of photosynthetic

Table 1 Percentage of grown algal clusters after various experimental conditions

\begin{tabular}{|c|c|c|c|c|c|c|c|}
\hline & \multirow[t]{2}{*}{ control } & \multicolumn{3}{|c|}{ space vacuum conditions } & \multicolumn{3}{|c|}{ Mars-analogue conditions } \\
\hline & & non- insolated & $0.1 \% \mathrm{~T}$ & $100 \% \mathrm{~T}$ & non-insolated & $0.1 \% \mathrm{~T}$ & $100 \% \mathrm{~T}$ \\
\hline grown clusters in $[\%]$ & $100 \%$ & $26 \%$ & $50 \%$ & $13 \%$ & $77 \%$ & $100 \%$ & $100 \%$ \\
\hline
\end{tabular}

Exposure conditions during 18 months exposure at the ISS. Space vacuum: $10^{-4}$ to $10^{-7} \mathrm{~Pa}$ and insolation with $110 \mathrm{~nm}<\lambda>1 \mathrm{~mm}$. Mars-analogue conditions: $10^{3} \mathrm{~Pa}$ Mars-analogue $\mathrm{CO}_{2}$-atmosphere and insolation with 200 $\mathrm{nm}\langle\lambda>1 \mathrm{~mm}$. Grown clusters in [\%] refer to the number of colony-forming algal clusters of the total number of prepared clusters. Control: freshly isolated photobiont clusters from frozen stored $X$. elegans thalli $\left(-20^{\circ} \mathrm{C}\right.$, same collection site). 

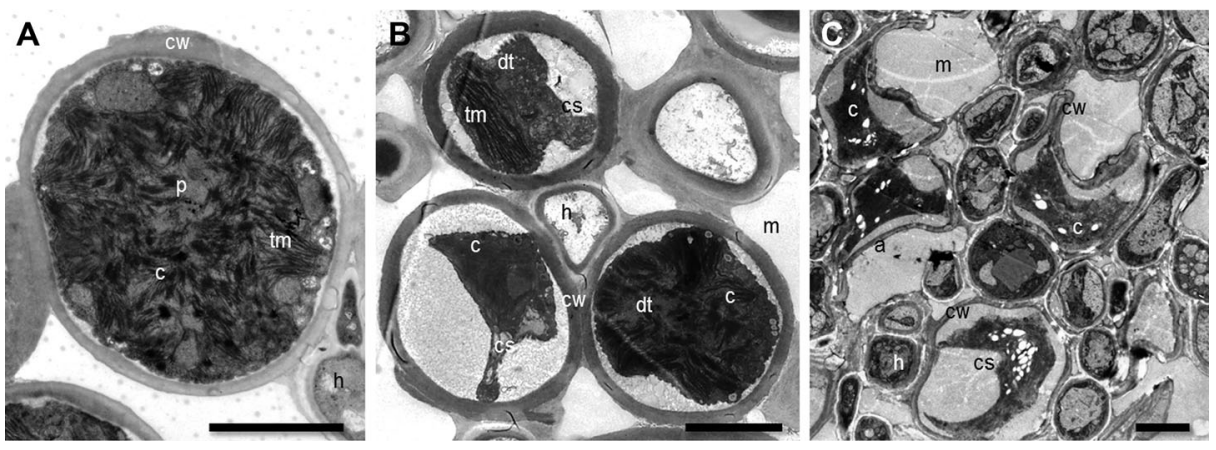

Fig. 3 Photobiont cells: normal appearance, partial and complete collapses. a Frozen control: regular appearance of Trebouxia photobiont cell. b Space vacuum, no insolation: partial and complete collapses, cell walls remain stable and unaffected. c Space vacuum, $0.1 \%$ T: collapsed protoplasts with collapsed walls. Abbreviations: $c w$ algal cell wall, $c$ chloroplast, $t m$ thylakoid membranes, $h$ hyphe, $m$ mucilage, $d t$ degraded thylakoid, $c s$ collapsed protoplast, $p$ pyrenoid, ep enlarged pyrenoid, $p g$ pyrenoglobuli. Scale bars indicate $5 \mu \mathrm{m}$

and metabolic activity by chlorophyll $a$ fluorescence and live/dead staining, respectively (Onofri et al. 2012; Brandt et al. 2015). None of the conditions tested in LIFE caused complete inhibition of growth or proliferation. The present results demonstrate that the lichen's viability was more preserved under Mars-analogue conditions compared to space vacuum. Insolation and/or UVradiation were not the major parameters affecting the post-exposure viability of the photobiont. The results of chlorophyll $a$ fluorescence showed lower rates of photosynthetic activity in the space vacuum samples than in the Mars-analogue ones (Brandt et al. 2015). The present cultivation assay of the photobiont confirmed this pattern, broadening it from mere metabolic activity to the actual ability of proliferation and growth. Besides $X$. elegans, other eukaryotic organisms were exposed to space or Mars-analogue conditions in the LIFE experiments on EXPOSE-E. All organisms revealed certain resistance to the hostile conditions (Horneck et al. 2012; Onofri et al. 2012), but the viability and proliferation ability of symbiotic $X$. elegans photobionts is not reached by other tested model organisms. In contrast to the photobiont of $X$. elegans, the cryptoendolithic fungi Cryomyces antarcticus and Cryptomyces minterii lost their colony-forming ability, though the former fungus showed $80 \%$ of intact cells in a PCR-assay after exposure to full insolation (Onofri et al. 2012).

Protective Screening Mechanisms The secondary lichen compound parietin, which is produced by the lichen fungus and deposited in the cortex of $X$. elegans is known for its blue

Table 2 Percentage of ultrastructural damage markers after various experimental conditions

\begin{tabular}{|c|c|c|c|c|c|c|c|c|}
\hline \multirow{2}{*}{$\begin{array}{l}\text { condition } \\
\text { insolation }\end{array}$} & \multicolumn{3}{|l|}{ space vacuum } & \multicolumn{3}{|l|}{ Mars-analogue } & \multicolumn{2}{|c|}{ control } \\
\hline & non-insolated & $0.1 \% \mathrm{~T}$ & $100 \% \mathrm{~T}$ & non-insolated & $0.1 \% \mathrm{~T}$ & $100 \% \mathrm{~T}$ & dry & frozen \\
\hline$\%$ collapsed protoplast & $61 \%$ & $97 \%$ & $85 \%$ & $57 \%$ & $48 \%$ & $51 \%$ & $70 \%$ & $44 \%$ \\
\hline$\%$ deformed walls & $25 \%$ & $85 \%$ & $79 \%$ & $27 \%$ & $16 \%$ & $35 \%$ & $49 \%$ & $33 \%$ \\
\hline n (algae cells) & 106 & 61 & 68 & 99 & 25 & 75 & 147 & 54 \\
\hline
\end{tabular}

Table 2 Exposure conditions during 18 months exposure at the ISS. Space vacuum: $10^{-4}$ to $10^{-7} \mathrm{~Pa}$ and insolation with $110 \mathrm{~nm}<\lambda>1 \mathrm{~mm}$. Mars-analogue conditions: $10^{3} \mathrm{~Pa}$ Mars-analogue $\mathrm{CO}_{2}$-atmosphere and insolation with $200 \mathrm{~nm}<\lambda>1 \mathrm{~mm}$. Frozen control: kept dark in freezer at $-20^{\circ} \mathrm{C}$. Dry control: dried sample kept dark at ambient temperature over silica-gel 

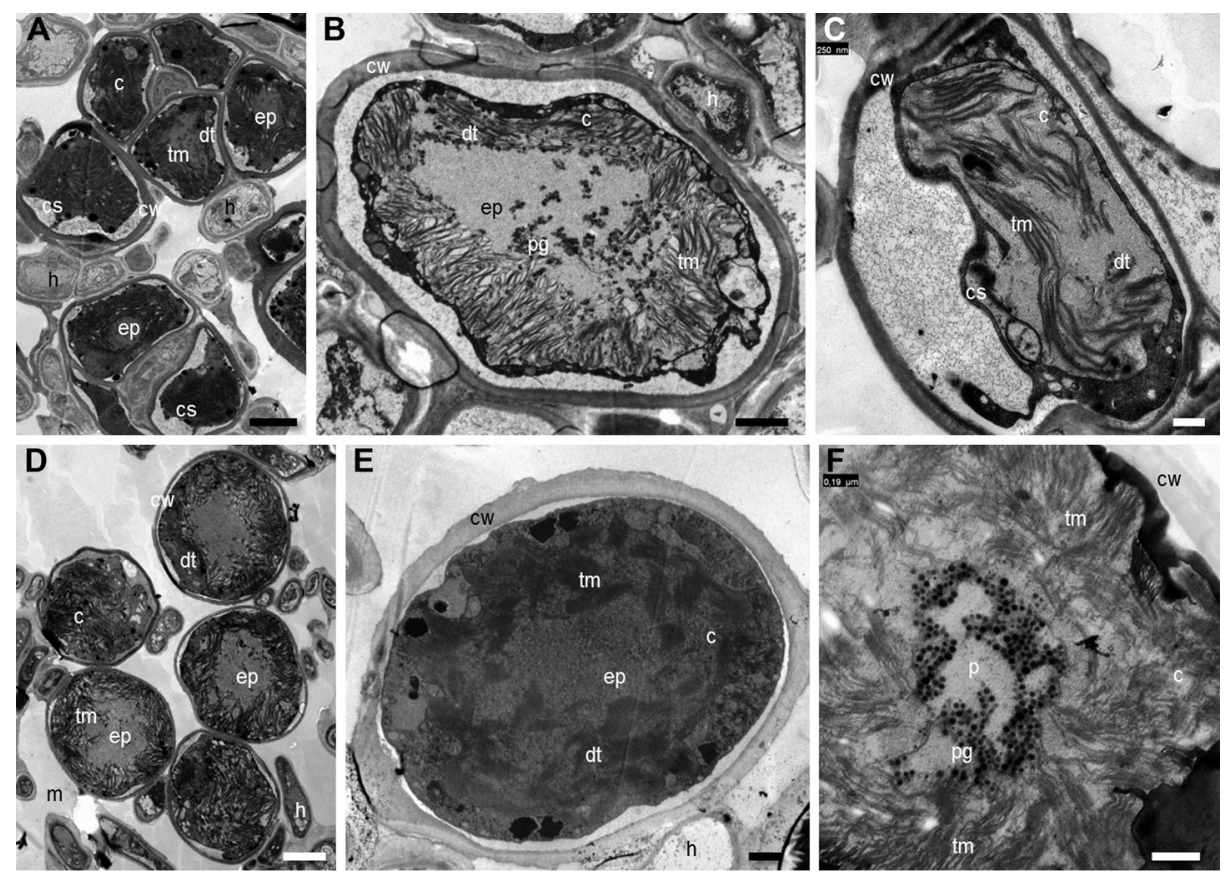

Fig. 4 Ultrastructural markers of desiccation. a Dry control: pyrenoid enlargement, partial protoplast collapses. b Space vacuum: degradation of thylakoid membranes, pyrenoid enlargement and photobiont shrinking. c Marsanalogue exposure: thylakoid degradation and partial collaps of the protoplast. d Mars-analogue exposure, $100 \% \mathrm{~T}$ : pyrenoid-enlargement, protoplast in regular shape. e Mars-analogue exposure, $0.1 \% \mathrm{~T}$ : pyrenoidenlargement, thylakoid membranes reduced and diffused. f Frozen control: pyrenoglobuli in pyrenoid. Abbreviations: $c w$ algal cell wall, $c$ chloroplast, $t m$ thylakoid membranes, $h$ hyphe, $m$ mucilage, $d t$ degraded thylakoid, cs collapsed protoplast, $p$ pyrenoid, ep enlarged pyrenoid, $p g$ pyrenoglobuli. Scale bars indicate $5 \mu \mathrm{m}$ in A, D, and $0.25 \mu \mathrm{m}$ in $\mathrm{B}, \mathrm{C}, \mathrm{E}, \mathrm{F}$

light and UV screening abilities (Solhaug \& Gauslaa 1996; Nybakken et al. 2004; Solhaug et al. 2010) efficiently protecting both symbionts. The amount of deposited parietin is stimulated by UV insolation in the natural habitat (Solhaug et al. 2003, Gauslaa \& McEvoy 2005) mostly leading to a parietin-bearing cortical layer of $20-65 \mu \mathrm{m}$ thickness on the cortex (Meeßen et al. 2013a). Thus, UVB, UVC and blue light are efficiently blocked by parietin in the upper cortex of the anhydrobiotic lichen (Gauslaa \& Solhaug 2004; Solhaug et al. 2010, Meeßen et al. 2013b). This observation is stressed by the result that the different insolation regimes applied in LIFE did not correlate to the recognised differences of photobiont viability. As discussed below, we suggest another parameter of the exposure conditions to account in large part for the observed loss of photobiont viability.

Temporary Ultrastructural Changes in Anhydrobiosis The key factor of lichens to survive extreme environmental conditions is anhydrobiosis (Crowe et al. 1992; Kranner et al. 2008). Both symbionts in lichens are adapted to poikilohydry resisting wet-dry cycles in their natural habitats including thallus water fluctuations between $<20$ and $>160 \%$ water per thallus dry weight (Kappen 1988). Anhydrobiosis is accompanied by visible alterations of the cellular ultrastructure (Honegger et al. 1996; Honegger 2003; de los Ríos et al. 2004, 2010). Photobiont cells are known to collapse temporarily upon dehydration under terrestrial conditions which appeared to be normal in the course of desiccation and rehydration (Brown et al. 
1987; Honegger et al. 1996; de los Ríos et al. 2004). Lichen photobionts quickly recover their spherical shape when re-hydrated (e.g. during TEM-preparation, Honegger et al. 1996; Honegger 2003).

Permanent Ultrastructural Damages by Long-Term Desiccation Permanent cellular collapses occur the more frequently the longer the dehydration period lasts and indicate desiccation-induced damage that may lead to death after six years of dry storage (Honegger 2003). In contrast, frozen storage $\left(>9\right.$ years at $\left.-20^{\circ} \mathrm{C}\right)$ of desiccated Trebouxia photobionts preserved their viability (Honegger et al. 1996; Honegger 2003). Collapsed photobiont cells as well as the observed degradation of thylakoid membranes were recognised as suitable markers for desiccation-induced impairment in the present study. Vacuum desiccation is considered the main process affecting biological samples when exposed to space vacuum (Horneck et al. 2010) while pressure conditions similar to those of Mars (e. g. at the upper boundary of Earth's biosphere) create desiccation-related effects as well (Horneck et al. 2010). Consistently, TEM micrograph analysis revealed that both conditions, LEO-vacuum and the $10^{3} \mathrm{~Pa}$ Mars-analogue atmosphere, caused an increased amount of collapsed protoplasts and cell walls, restricting the photobiont's capacity of rehydration. Concerning the degradation of the thylakoid membranes and pyrenoid enlargement, all exposed samples showed a higher frequency of both damage markers which were unrelated to certain exposure conditions but more pronounced than in the control groups. These results stress the deleterious effect of vacuum-induced, long-time desiccation in the space exposed samples, while - due to the higher atmospheric pressure the desiccation condition under Mars-analogue conditions were less extreme and therefore the samples were less impacted.

Acknowledgments The authors would like to express their sincere gratitude to the German Federal Ministry of Economics and Technology (BMWi) and the German Aerospace Centre (DLR) for funding the work of Annette Brandt (50BW1216) and J.-P. de Vera (50WB0614). Our special thanks are due to ESA and to the simulation facilities at DLR Cologne, especially Elke Rabbow, for MGR simulation, sample integration, and for invaluable advice. We would also like to thank Joachim Meeßen for stimulating and critical discussions. Moreover, we thank the anonymous reviewers for constructive feedback.

\section{References}

Ahmadjian V (1967) A guide to the algae occurring as lichen symbionts: isolation, culture, cultural physiology, and identification. Phycologia 6(2):127-160

Ascaso C, Brown DH, Rapsch S (1988) The effect of desiccation on the pyrenoid structure in the oceanic lichen Parmelia laevigata. Lichenologist 20(1):31-39

Ascaso C, Valladares F, de los Ríos A (1995) New ultrastructural aspects of pyrenoids of the lichen photobiont Trebouxia (Mikrothamniales, Chlorophyta). J Phycol 31(1):114-119

Baqué M, Scalzi G, Rabbow E, Rettberg P, Billi D (2013) Biofilm and planktonic lifestyles differently support the resistance of the desert cyanobacterium Chroococcidiopsis under space and Martian simulations. Orig Life Evol Biosph 43(4-5):377-389

Berger T, Hajek M, Bilski P, Körner C, Vanhavere F, Reitz G (2012) Cosmic radiation exposure of biological test systems during the EXPOSE-E mission. Astrobiology 12(5):387-392

Brown DH, Ascaso C, Rapsch S (1987) Ultrastructural changes in the pyrenoid of the lichen Parmelia sulcata stored under controlled conditions. Protoplasma 136(2-3):136-144

Brandt A, de Vera JP, Onofri S, Ott S (2015) Viability of the lichen Xanthoria elegans and its symbionts after 18 months of space exposure and simulated Mars conditions on the ISS. Int J Astrobiol 14(3):411-425

Cockell CS, Rettberg P, Rabbow E, Olsson-Francis K (2011) Exposure of phototrophs to 548 days in low earth orbit: microbial selection pressures in outer space and on early Earth. Isme J 5(10):1671-1682 
Crowe JH, Hoekstra FA, Crowe LM (1992) Anhydrobiosis. Annu Rev Physiol 54(1):579-599

de la Torre NR, Sancho LG, Pintado A, Rettberg P, Rabbow E, Panitz C, Deutschmann U, Reina M, Horneck G (2007) BIOPAN experiment LICHENS on the foton M2 mission: Pre-flight verification tests of the Rhizocarpon geographicum-granite ecosystem. Adv Space Res 40(11):1665-1671

de la Torre R, Sancho LG, Horneck G, de los Ríos A, Wierzchos J, Olsson-Francis K, Cockell CS, Rettberg P, Berger T, de Vera JP, Ott S, Frías JM, Gonzalez PM, Lucas MM, Reina M, Pintado A, Demets R (2010) Survival of lichens and bacteria exposed to outer space conditions-results of the LITHOPANSPERMIA experiments. Icarus 208(2):735-748

de la Vega UP, Rettberg P, Reitz G (2007) Simulation of the environmental climate conditions on Martian surface and its effect on Deinococcus radiodurans. Adv Space Res 40(11):1672-1677

de los Ríos A, Wierzchos J, Sancho LG, Ascaso C (2004) Exploring the physiological state of continental Antarctic endolithic microorganisms by microscopy. FEMS Microbiol Ecol 50(3):143-152

de los Ríos A, Ascaso C, Wierzchos J (2010) Study of lichens with different state of hydration by the combination of low temperature scanning electron and confocal laser scanning microscopies. Int Microbiol 2(4):251-257

de Vera JP, Horneck G, Rettberg P, Ott S (2003) The potential of the lichen symbiosis to cope with extreme conditions of outer space-I. Influence of UV radiation and space vacuum on the vitality of lichen symbiosis and germination capacity. Int J Astrobiol 1(4):285-293

de Vera JP, Horneck G, Rettberg P, Ott S (2004a) The potential of the lichen symbiosis to cope with the extreme conditions of outer space-II: germination capacity of lichen ascospores in response to simulated space conditions. Adv Space Res 33(8):1236-1243

de Vera JP, Horneck G, Rettberg P, Ott S (2004b) In the context of panspermia: may lichens serve as shuttles for their bionts in space? In: Proceedings of the Third European Workshop on Exo-Astrobiology, 18-20 Nov 2003, Madrid, ESA SP-545, ESA ESTEC, The Netherlands, pp. 197-198

de Vera JP, Rettberg P, Ott S (2008) Life at the limits: capacities of isolated and cultured lichen symbionts to resist extreme environmental stresses. Orig Life Evol Biosph 38(5):457-468

de Vera JP, Möhlmann D, Butina F, Lorek, A., Wernecke, R. \& Ott S (2010) Survival potential and photosynthetic activity of lichens under Mars-like conditions: a laboratory study. Astrobiology 10(2):215-227

de Vera JP, Ott S (2010) Resistance of symbiotic eukaryotes. Survival to simulated space conditions and asteroid impact cataclysms. In: Seckbach J, Grube M (eds) Symbioses and Stress: Joint ventures in biology. Springer, Netherlands, pp. 595-611

Gauslaa Y, Solhaug KA (2004) Photoinhibition in lichens depends on cortical characteristics and hydration. Lichenologist 36(2):133-143

Gauslaa Y, McEvoy M (2005) Seasonal changes in solar radiation drive acclimation of the sun-screening compound parietin in the lichen Xanthoria parietina. Basic Appl Ecol 6(1):75-82

Hájek J, Váczi P, Barták M, Jahnová L (2012) Interspecific differences in cryoresistance of lichen symbiotic algae of genus Trebouxia assessed by cell viability and chlorophyll fluorescence. Cryobiology 64(3):215-222

Honegger R (2003) The impact of different long-term storage conditions on the viability of lichen-forming ascomycetes and their green algal photobiont, Trebouxia spp. Plant Biology 5(3):324-330

Honegger R, Peter M, Scherrer S (1996) Drought-induced structural alterations at the mycobiont-photobiont interface in a range of foliose macrolichens. Protoplasma 190(3-4):221-232

Horneck G, Stöffler D, Ott S, Hornemann U, Cockell CS, Moeller R, Meyer C, de Vera JP, Fritz J, Schade S, Artemieva NA (2008) Microbial rock inhabitants survive hypervelocity impacts on Mars-like host planets: first phase of lithopanspermia experimentally tested. Astrobiology 8(1):17-44

Horneck G, Klaus DM, Mancinelli RL (2010) Space microbiology. Microbiol Mol Biol Rev 74(1):121-156

Horneck G, Moeller R, Cadet J, Douki T, Mancinelli RL, Nicholson WL, Panitz C, Rabbow E, Rettberg P, Spry A, Stackebrandt E, Vaishampayan P, Venkateswaran KJ (2012) Resistance of bacterial endospores to outer space for planetary protection purposes - experiment PROTECT of the EXPOSE-E mission. Astrobiology 12(5):445-456

Kappen L (1988) Ecophysiological relationships in different climatic regions. Handbook of Lichenology 2:37-100

Kranner I, Beckett R, Hochman A, Nash III TH (2008) Desiccation-tolerance in lichens: a review. Bryologist 111(4):576-593

Meeßen J, Sánchez FJ, Brandt A, Balzer EM, de la Torre R, Sancho LG, de Vera JP, Ott S (2013a) Extremotolerance and resistance of lichens: comparative studies on five species used in astrobiological research I. Morphological and anatomical characteristics. Orig Life Evol Biosph 43(3):283-303

Meeßen J, Sánchez FJ, Sadowsky A, de la Torre R, Ott S, de Vera JP (2013b) Extremotolerance and resistance of lichens: comparative studies on five species used in astrobiological research II. Secondary lichen compounds. Orig Life Evol Biosph 43(6):501-526

Meeßen J, Backhaus T, Sadowsky A, Mrkalj M, Sánchez FJ, de la Torre R, Ott S (2014) Effects of UVC 254 nm on the photosynthetic activity of photobionts from the astrobiologically relevant lichens Buellia frigida and Circinaria gyrosa. Int J Astrobiol 13(4):340-352 
Nybakken L, Solhaug KA, Bilger W, Gauslaa Y (2004) The lichens Xanthoria elegans and Cetraria islandica maintain a high protection against UV-B radiation in Arctic habitats. Oecologia 140(2):211-216

Olsson-Francis K, de la Torre R, Cockell CS (2010) Isolation of novel extreme-tolerant cyanobacteria from a rock-dwelling microbial community by using exposure to low Earth orbit. Appl Environ Microbiol 76(7): $2115-2121$

Onofri S, Selbmann L, Zucconi L, Pagano S (2004) Antarctic microfungi as models for exobiology. Planet Space Sci 52(1):229-237

Onofri S, de la Torre R, de Vera JP, Ott S, Zucconi L, Selbmann L, Scalzi G, Vankateswaran KJ, Rabbow E, Sánchez Iñigo FJ, Horneck G (2012) Survival of rock-colonizing organisms after 1.5 years in outer space. Astrobiology 12(5):508-516

Øvstedal DO, Lewis Smith RI (2001) Lichens of Antarctica and South Georgia. Cambridge University Press, pp. 361-363

Rabbow E, Rettberg P, Barczyk S, Bohmeier M, Parpart A, Panitz C, Horneck G, von Heise-Rotenburg R, Hoppenbrouwers T, Willnecker R, Baglioni P, Demets R, Dettmann J, Reitz G (2012) EXPOSE-E: an ESA astrobiology mission 1.5 years in space. Astrobiology 12(5):374-386

Raggio J, Pintado A, Ascaso C, de la Torre R, de los Ríos A, Wierzchos J, Horneck G, Sancho LG (2011) Whole lichen thalli survive exposure to space conditions: results of LITHOPANSPERMIA experiment with Aspicilia fruticulosa. Astrobiology 11(4):281-292

RedShift Report: Reviewers: van Bavinchove C, Beuselinck T (2011) EXPOSE: Environmental history by calculation - EXPOSE-E simulation results. Ref: EXP-RP-017-RS ISS. A(2). RedShift Design and Engineering BVBA (125 pp)

Sánchez FJ, Mateo-Martí E, Raggio J, Meeßen J, Martínez-Frías J, Sancho LG, Ott S, de la Torre R (2012) The resistance of the lichen Circinaria gyrosa (nom. Provis.) towards simulated Mars conditions - a model test for the survival capacity of an eukaryotic extremophile. Planet Space Sci 72(1):102-110

Sánchez FJ, Meeßen J, Ruiz M, Sancho LG, Ott S, Vílchez C, Horneck G, Sadowsky A, de la Torre R (2014) UV-C tolerance of symbiotic Trebouxia sp. in the space-tested lichen species Rhizocarpon geographicum and Circinaria gyrosa: role of the hydration state and cortex/screening substances. Int J Astrobiol 13(1):1-18

Sancho LG, de la Torre R, Horneck G, Ascaso C, de los Ríos A, Pintado A, Wierzchos J, Schuster M (2007) Lichens survive in space: results from the 2005 LICHENS experiment. Astrobiology 7(3):443-454

Scalzi G, Selbmann L, Zucconi L, Rabbow E, Horneck G, Albertano P, Onofri S (2012) LIFE experiment: isolation of cryptoendolithic organisms from Antarctic colonized sandstone exposed to space and simulated Mars conditions on the International Space Station. Orig Life Evol Biosph 42(2-3):253-262

Solhaug KA, Gauslaa Y (1996) Parietin, a photoprotective secondary product of the lichen Xanthoria parietina. Oecologia 108(3):412-418

Solhaug KA, Gauslaa Y, Nybakken L, Bilger W (2003) UV-induction of sun-screening pigments in lichens. New Phytol 158(1):91-100

Solhaug KA, Larsson P, Gauslaa Y (2010) Light screening in lichen cortices can be quantified by chlorophyll fluorescence techniques for both reflecting and absorbing pigments. Planta 231(5):1003-1011

Stöffler D, Horneck G, Ott S, Hornemann U, Cockell CS, Moeller R, Meyer C, de Vera JP, Fritz J, Artemieva NA (2007) Experimental evidence for the potential impact ejection of viable micro-organisms from Mars and Mars-like planets. Icarus 186(2):585-588 